\title{
Predictors of respiratory failure in acute organophosphorus compound poisoning
}

\author{
Devee Anjana', Dutta Neeta ${ }^{2}$ \\ Received on October 10, 2018; editorial approval on November 29, 2018
}

\begin{abstract}
Introduction: Poisoning with Organophosphorus (OP) compounds is a common toxicological emergency in an agricultural country like India because of its ease of availability. Fatality in organophosphorus toxicity is mostly due to respiratory failure and cardiovascular collapse. Studies have shown that respiratory failure is one of the most common complications in the acute stage. Objectives: The aim of this study was to assess the effectiveness of Glasgow Coma Scale (GCS), Poisoning Severity Scale (PSS) and Peradeniya Organophosphorus Poisoning (POP) Score in predicting the development of acute respiratory failure following Organophosphorus compound poisoning. Materials and methods: A prospective, observational study was carried out over a period of one year from July 2017 to June 2018. The diagnosis was based on history of exposure to organophosphorus compound, along with symptoms and clinical signs of cholinergic crisis. Patients were followed up for 24 hours after the exposure to OP compound and were examined for development of acute respiratory failure. Results: Out of the total 110 patients in the study, 61(55.45\%) were males and 49(44.54\%) were females. The mean age was $30.03 \pm 10.242$ years. Twenty-nine $(26.36 \%)$ patients developed acute respiratory failure. Patients with GCS less than 10, PSS of 3 or more and POP scale of moderate and severe poisoning more commonly developed acute respiratory failure. Conclusion: A low GCS $(<10)$, PSS of 3 or more and a POP grade of moderate and severe poisoning had a strong association with the development of acute respiratory failure.
\end{abstract}

Keywords: Toxicological emergency; Peradeniya OP scale; Poisoning Severity Score.

\section{INTRODUCTION}

Poisoning has become a common social and medical problem worldwide causing significant morbidity and mortality. ${ }^{1}$ According to World Health Organization (WHO) reports, ingestion of pesticides is now the most common method of suicide worldwide. ${ }^{2}$

As per National Crime Records Bureau (2016) report, 27.9\% of suicides were committed by consuming poisons in India in the year 2015. ${ }^{3}$ Out of all pesticide related deaths, poisoning with Organophosphorous compounds account for two-thirds of all the deaths. ${ }^{4}$

Organophosphorous compounds are organic derivatives of phosphoric and phosphonic acid and a group of cholinesterase inhibiting pesticides. They cause phosphorylation of the enzyme acetylcholine esterase (AChE) rendering it inactive. The binding of the OP compound to the enzyme is irreversible, except with early pharmacological intervention. The inactive, phopshorylated AChE is unable to hydrolyse acetylcholine (ACh) leading to its accumulation in the neuronal synapses and neuromuscular junctions (NMJ). ${ }^{5}$ The clinical manifestations of organophosphorus compounds poisoning is due to excessive acetylcholine at the muscarinic and nicotinic receptors resulting in a syndrome of cholinergic crisis. $^{5}$

The early causes of death in acute organophosphorus compound poisoning are due to respiratory failure from CNS depression, bronchospasm, respiratory muscle paralysis or due to ventricular arrhythmias. ${ }^{6}$ Respiratory failure, which may be early or late, is the most common complication following OP poisoning. ${ }^{7,8}$ Prompt treatment with antidotes and ventilation can reduce the mortality.

\footnotetext{
Address for correspondence:

${ }^{1}$ Associate Professor (Corresponding author)

Mobile: +919435040249

E-mail: anjana_devee@rediffmail.com

${ }^{2}$ Post graduate trainee

Mobile: +919954323860

E-mail: neetaemgmch@gmail.com

Department of Emergency Medicine, Gauhati Medical College

\& Hospital, Guwahati-781032
} poisoning. Int J Health Res Medico Leg Prae 2019 January;5(1):15-18. DOI 10.31741/ijhrmlp.v5.i1.2018.5 
This study was undertaken to identify the factors that help in predicting early respiratory failure and the need for mechanical ventilation in patients with Organophosphorus compound poisoning.

\section{MATERIALS AND METHODS}

This was a prospective, observational study carried out over a period of 1 year from July 2017 to June 2018. A total of 110 patients presenting to Emergency Medicine Department of Gauhati Medical College and Hospital within 24 hours of Organophosphorus poisoning were included in the study. The exclusion criteria were age $<18$ years, presentation after 24 hours of ingestion of OP compound, patients with known neuromuscular disease, underlying pulmonary disease and OP poisoning in pregnant females.

On admission, primary survey with simultaneous resuscitation and decontamination was carried out, followed by detailed secondary survey with record of demographic factors, time and mode of exposure to OP compound, type of compound patient was exposed to, symptoms, previous medical and surgical illness and any pre-hospital care received.

For all the patients, Glasgow coma scale (GCS), Poisoning Severity Scale (PSS), and Peradeniya Organophosphorus poisoning (POP) score were assessed at the time of admission.

The Poisoning Severity Score (PSS) was developed by European Association of Poison Centres and Clinical

Table 1 Peradeniya OP Poisoning Scale

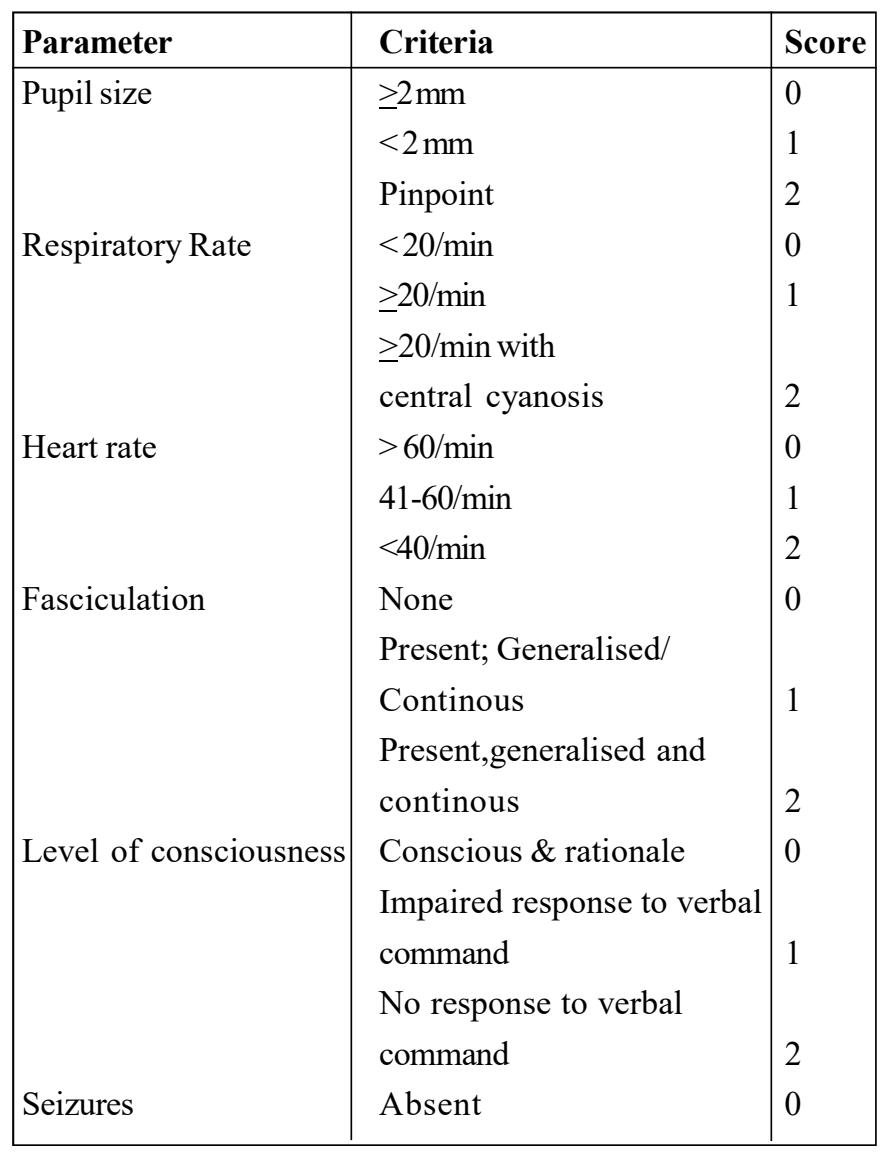

Toxicologists (EAPCCT), International Programme on Chemical Safety (IPCS), and the Commission of the European Union using a collection of clinical signs and symptoms for different organ systems to assign a score of 0 to $4 .^{9}$

The Peradeniya OP Poisoning Scale was introduced by Senanayake et al. in 1993 as a clinical scale to assess the severity of Organophosphorus intoxication. ${ }^{10}$ It takes into account the 6 common clinical features of OP Poisoning (Table 1). A total of 0-3 is considered as mild poisoning, 4 7 as moderate poisoning and 8-11 as severe poisoning.

Relevant blood investigations including arterial blood gas analysis was done in all patients. Patients were followed up for 24 hours after exposure to OP compound and were examined for development of acute respiratory failure. Patients were diagnosed as having early respiratory failure if $\mathrm{PaO}_{2}<60$ $\mathrm{mm} \mathrm{Hg}$ and/or $\mathrm{PaCO}_{2}>50 \mathrm{mmHg}$ were detected within 24 hours. Categorical variables were analyzed accordingly with the chi-square test or Fisher exact test. For numerical variables, analysis of variance (ANOVA) test was used. For all statistical analyses, a probability ( $p$ value) of less than 0.05 was considered to be statistically significant.

\section{RESULTS}

A total of 110 patients with a history of exposure to organophosphorus compounds presenting within 24 hours were evaluated in the study. Out of the total study population, $29(26.36 \%)$ patients developed early respiratory failure, i.e., respiratory failure in the first 24 hours. The mean age was $30.03 \pm 10.242$ years. Majority $(41.81 \%)$ of the patients belonged to the age group of 21-30 years (Figure 1). 61 patients $(55.45 \%)$ were males and $49(44.54 \%)$ were females.

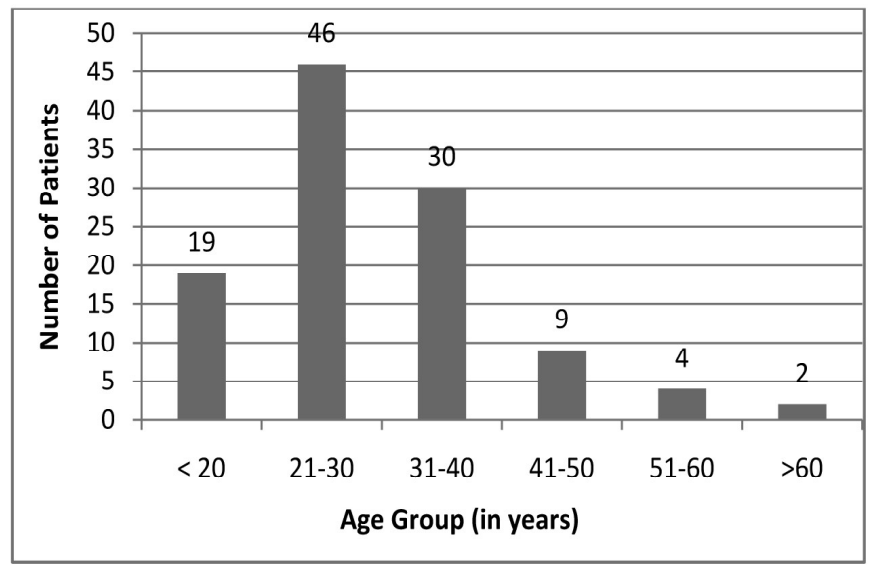

Figure 1 Bar Diagram showing age wise distribution of patients

The mode of poisoning was intentional in 108(98.18\%) patients and only $2(1.18 \%)$ patients had accidental exposure to the OP compound. There were no homicidal cases in our study. The most common route of exposure was ingestion in $98.18 \%$ and cutaneous in $1.18 \%$ of the patients. Fifty-one patients $(46.36 \%)$ presented within 3 hours and 59 patients $(53.63 \%)$ presented after 3 hours of exposure (mean $5.4 \pm 4.60$ hours).

Out of the total 29 patients developing respiratory failure, 18 
$(62.06 \%)$ patients had developed Type 1 respiratory failure while $11(37.93 \%)$ patients had developed Type 2 respiratory failure.

It was found that54 patients (49.09\%) had a GCS between 11-15, 33 patients $(30 \%)$ had a GCS between $8-10$ and 23 patients $(20.90 \%)$ had a GCS between 3-7. Among the patients developing early respiratory failure 18 patients had GCS between 3-7 and 11 patients had GCS between 8-10. Patients with a GCS between 1115 did not develop respiratory failure. This was statistically significant with $\mathrm{p}$ value $<0.0001$ (Table 2).

Table 2 Distribution of patients with respiratory failure according to GCS

\begin{tabular}{|l|c|l|l|}
\hline GCS & Total Patients & $\begin{array}{l}\text { Patients with } \\
\text { respiratory failure }\end{array}$ & Percentage \\
\hline $11-15$ & 54 & 0 & $0 \%$ \\
\hline $8-10$ & 33 & 11 & $37.93 \%$ \\
\hline $3-7$ & 23 & 18 & $62.06 \%$ \\
\hline
\end{tabular}

In our study, the mean Poisoning Severity Score (PSS) was $1.85 \pm 0.993$. All patients with a PSS of 4 developed respiratory failure whereas $76.92 \%$ with a PSS of 3 and $14.81 \%$ of patients with a PSS of 2 developed respiratory failure. No patients with a PSS of 0 or 1 developed respiratory failure, which was significant ( $p$ value $<0.0001)$. Table 3 shows the distribution of patients according to Poisoning Severity Score.

Table 3 Distribution of patients with respiratory failure according to PSS

\begin{tabular}{|l|l|l|l|}
\hline PSS & $\begin{array}{l}\text { Total no. } \\
\text { of patients }\end{array}$ & $\begin{array}{l}\text { No. of patients } \\
\text { with respiratory failure }\end{array}$ & $\begin{array}{l}\text { Percent- } \\
\text { age }\end{array}$ \\
\hline 0 (None) & 10 & 0 & $0 \%$ \\
\hline 1 (Minor) & 42 & 0 & $0 \%$ \\
\hline 2 (Moderate) & 27 & 4 & $14.81 \%$ \\
\hline 3 (Severe) & 26 & 20 & $76.92 \%$ \\
\hline 4 (Fatal) & 5 & 5 & $100 \%$ \\
\hline
\end{tabular}

As per the Peradeniya Organophosphorus Poisoning (POP) scale applied at the time of admission, 49(44.54\%) patients had mild poisoning, 52(47.27\%) patients had moderate poisoning and $9(8.18 \%)$ patients had severe poisoning. All the 9 patients with severe grade of poisoning developed respiratory failure, 20 patients with moderate grade of poisoning developed respiratory failure, while none of the patients with mild grade of poisoning developed respiratory failure (Table 4). This was statistically significant.

Table 4 Distribution of patients with respiratory failure according to POP scale

\begin{tabular}{|l|l|l|l|}
\hline POP scale & $\begin{array}{l}\text { Total no. } \\
\text { of patients }\end{array}$ & $\begin{array}{l}\text { Patients with } \\
\text { respiratory failure }\end{array}$ & $\begin{array}{l}\text { Percent- } \\
\text { age }\end{array}$ \\
\hline Mild & 49 & 0 & $0 \%$ \\
\hline Moderate & 52 & 20 & $38.46 \%$ \\
\hline Severe & 9 & 9 & $100 \%$ \\
\hline
\end{tabular}

\section{DISCUSSION}

In this study, age of the patients ranged from 18 to 67 years (mean $30.018 \pm 10.287$ years). Majority of the patients (41.81\%) belonged to the age group of 21-30 years. The findings are similar to the studies done by Shaikh MA and Patil SL. ${ }^{11,12}$ Males constituted 55.45\% (61 patients) and females constituted $44.54 \%$ (49 patients) of the total study population. These findings were similar to studies conducted by Tsai et a ${ }^{13}$ and Mutalik et al. ${ }^{14}$ However, studies conducted by Dubey et $a 1^{15}$ and Soni et $a 1^{16}$ had a higher majority of female population.

The mode of poisoning was intentional for suicidal attempt in $108(98.18 \%)$ patients, whereas accidental in only $2(1.18 \%)$ patients. This was similar to observations made by Ahmed et $\mathrm{al}^{17}$ and Bandhay et al. ${ }^{18}$ A high rate of suicidal attempts with organophosphorus compounds can be explained by the fact that it is cheap, easily available and associated with a high fatality. Moreover, accidental and /or occupational exposure of OP compounds may not be always reported due to mild or atypical symptoms. However, Khan et al reported accidental mode of poisoning in $87.3 \%$ of cases. ${ }^{19}$

The route of exposure was ingestion in $98.18 \%$ of cases while it was inhalation and/or dermal in $1.18 \%$ of cases. This is in accordance with suicide being the most common mode of poisoning. The mean time of presentation after exposure was 5.4 hours \pm 4.60 . In this study, 51(46.36\%) patients presented within 3 hours of exposure, whereas 59(53.63\%) patients presented after 3 hours of exposure to OP compound. Out of 110 patients in total, 29(26.36\%) patients developed acute respiratory failure within 24 hours after exposure.

Type 1 respiratory failure was observed in 18(62.06\%) patients whereas $11(37.93 \%)$ patients developed Type 2 respiratory failure. Goswamy et al in their study observed that $79.41 \%$ had developed Type 1 respiratory failure and $20.58 \%$ had Type 2 respiratory failure. ${ }^{20}$ While $49.09 \%$ of our patients had a Glasgow coma scale (GCS) of more than $10,30 \%$ had a GCS between $8-10$ and $20.90 \%$ had GCS less than 8 . Out of the 29 patients developing respiratory failure, no patient had GCS between 11-15, while 37.93\% had GCS between 8-10 and 62.06\% had GCS between 3-7 which is comparable to the studies by Eranaik et $\mathrm{al}^{21}$ and Soni et al. ${ }^{16}$ A low GCS of the patients correlated significantly with the development of respiratory failure.

According to Peradeniya Organophosphorus Poisoning (POP) scale, patients were graded as having mild, moderate or severe degree of poisoning. In our study, $38.46 \%$ of patients with moderate poisoning as per POP scale developed respiratory failure whereas $100 \%$ of the patients with severe grade of poisoning developed respiratory failure. Patil et al in their study observed that $62.5 \%$ of patients with moderate poisoning and $100 \%$ of patients with severe poisoning developed respiratory failure. ${ }^{22}$ The result shows that the Peradeniya OP poisoning scale is a good predictor of development of respiratory failure and morbidity in these cases. 
Patients were also assigned a score based on the Poisoning Severity Score. The mean PSS was $1.85 \pm 0.993$ which is comparable to the observation made by Akdur et al. ${ }^{23}$ All patients with a PSS of 4 developed respiratory failure whereas $76.92 \%$ with a PSS of 3 (severe) and $14.81 \%$ of patients with a PSS of 2 (moderate) developed respiratory failure. No patients with a PSS of 0 (None) or 1 (Minor) developed respiratory failure. This was statistically significant with a $p$ value $<0.0001$. Chandrasekhar et al in their study of 100 patients observed that Poisoning Severity Score (PSS) in a good clinical tool is predicting the outcome in acute OP poisoning. ${ }^{24}$ Sam et al and Casey et al also observed a significant correlation between the PSS and the outcome, with a higher PSS in the non-survival group..$^{25,26}$

\section{CONCLUSION}

Clinical scoring systems like Glasgow Coma Scale (GCS), Poisoning Severity Score (PSS) and Peradeniya organophosphorus compound Poisoning (POP) scale are useful tools in predicting the development of respiratory failure in patients with acute organophosphorus compound poisoning. A low GCS $(<10)$, PSS of 3 or more and a POP grade of moderate and severe had a strong association with development of respiratory failure.

Conflict of interest: None declared.

Ethical clearance: Taken.

Source of funding: None declared.

Declarations: (1) The article is original with the author(s) and does not infringe any copyright or violate any other right of any third party. (2) The article has not been published (whole or in part) elsewhere, and is not being considered for publication elsewhere in any form, except as provided herein. (3) All author(s) have contributed sufficiently in the article to take public responsibility for it and (4) all author(s) have reviewed the final version of the above manuscript and approved it for publication.

\section{REFERENCES}

1. Howlader MA, Sardar MH, Amin MR, Morshed MG, Islam MS, Uddin MZ, et al. Clinico-epidemiological pattern of poisoning in a tertiary level hospital. J of Dhaka Med College 2008;17(2):111-5.

2. Bertolote JM, Fleischmann A, Butchart A, Besbelli N. Suicide, suicide attempts and pesticides: a major hidden public health problem. Bull World Health Organ 2006;84(4):260.

3. Accidental Deaths and Suicides in India 2015. In National Crime Records Bureau, Ministry of Home Affairs, New Delhi, Government of India 2016. p. 205.

4. Eddleston M. Patterns and problems of deliberate self-poisoning in the developing world. Q J Med 2000;93:715-31.

5. Eddleston M. Insecticides: Organic Phosphorous compounds and Carbamates. In: Hoffman RS, Howland MA, Lewin NA, Nelson LS, Goldfrank LR, editors. Goldfrank's toxicologic emergencies $10^{\text {th }}$ ed. New York: McGraw-Hill Education; 2015. p. 1409-20.

6. Eddleston M, Mohamed F, Davies JOJ. Respiratory failure in acute organophosphorus pesticide self-poisoning. Q J Med 2006;99:513-22.

7. Goel A, Joseph S, Dutta TK. Organophosphate Poisoning: Predicting the need for ventilator support. JAPI 1998;46:786-90.

8. Avasthi G, Singh G. Serial neuro-electrophysiological studies in acute organophosphate poisoning-correlation with clinical findings, serum cholinesterase levels and atropine dosages. JAPI 2000;48(8):794-9.

9. Persson HE, Sjoberg GK, Haines JA, de Garbino JP. Poisoning severity score. Grading of acute poisoning. J Toxicol: Clin toxicol 1998;36(3):205-13.

10. Senanayake N, De Silva HJ, Karalliedde L. A scale to assess severity in organophosphorus intoxication: POP scale. Hum Exp Toxicol 1993;12(4):297-9.

11. Shaikh MA. Mortality in patients presenting with organophosphorus poisoning at Liaquat University of Medical and Health Sciences. Pak J Med Sci 2011;27(5):1022-4.

12. Patil SL, Vasepalli P. Prognostic value of clinical and lab parameters in assessing the severity of organophosphorus compound poisoning. IJBAMR 2014;4(1):77-91.

13. Tsai JR, Sheu CC, Cheng MH, Hung JY, Wang CS, Chong IW, et al. Organophosphate poisoning: 10 years of experience in southern Taiwan. The Kaohsiung J Med Sci 2007;23(3):112-9.

14. Mutalik GS, Wadia GS, Pai VR. Poisoning by diazinon, an organophosphorusinstecide. J Ind Med Assoc 1962;38:67-71.

15. Dubey TN, Yadav S, Kawre KK. Correlation of Severity of Organophosphorus Poisoning as Assessed by Peradeniya Organophosphorus Poisoning Scale with Serum Amylase and CPK Level. IJCMR 2016;3(9):2534-7.

16. Soni P, Solu MG, Garg V, Pathria A, Shah S, Mundra A. Organophosphate Poisoning Predicting the Need for Mechanical Ventilator Support. Int J of Sci Study 2016;4(6):168-72.

17. Ahmed SM, Das B, Nadeem A, Samal RK. Survival pattern in patients with acute organophosphate poisoning on mechanical ventilation: A retrospective intensive care unit-based study in a tertiary care teaching hospital. Indian J Anaesth 2014;58(1):11.

18. Banday TH, Tathineni B, Desai MS, Naik V. Predictors of morbidity and mortality in organophosphorus poisoning: a case study in rural hospital in Karnataka, India. North Am J Med Sci 2015;7(6):259.

19. Khan FY, Kamha AM, Ibrahim AS, D'souza A. One-year study of patients with acute organophosphate insecticide poisoning admitted to the intensive care unit of Hamad General Hospital, Doha, State of Qatar. J Em Med Trauma Acute Care 2006;6(2):16-20.

20. Goswamy R, Chaudhuri A, Mahashur AA. Study of respiratory failure in organophosphate and carbamate poisoning. Heart and lung: the journal of critical care 1994;23(6):466-72.

21. Eranaik KB, Nagraj BL. A study of predicting the need for ventilator support and outcome in organophosphorus poisoning. J Evid Based Med Healthc 2017;4(29):1674-81.

22. Patil SL, Vasepalli P. Prognostic value of clinical and lab parameters in assessing the severity of organophosphorus compound poisoning. Indian J Basic App Med Res 2014:4(1);77-91.

23. Hassan NA, Madboly AG. Correlation between serum creatine phosphokinase and severity of acute organophosphorus poisoning: A prospective clinical study (2012-2013). IOSR J Environ Sci, Toxicol Food Tech 2013;4:18-29.

24. Chandrasekhar S, Rahim MA, Quraishi SM, Theja CR, Kiran KS. An observational clinical study of assessing the utility of PSS (Poison Severity Score) and GCS (Glasgow Coma Scale) scoring systems in predicting severity and clinical outcomes in op poisoning. J Evid Based Med Healthc 2017;4(38):2325-32.

25. Sam KG, Kondabolu K, Pati D, Kamath A, Kumar GP, Rao PG. Poisoning severity score, APACHE II and GCS: effective clinical indices for estimating severity and predicting outcome of acute organophosphorus and carbamate poisoning. $\mathrm{J}$ forensic legal med 2009;16(5):239-47.

26. Casey PB, Dexter EM, Michell J, Vale JA. The prospective value of the IPCS/EC/EAPCCT poisoning severity score in cases of poisoning. J Toxicol Clinical Toxicol 1998;36(3):215-7. 